\title{
Changing Supplying Oil and Connecting Rod Bearings Conditions of the Crankshaft of an Internal Combustion Engine in Operation
}

\author{
${ }^{1}$ IInur R. Akhmetzyanov, ${ }^{2}$ Alexander T. Kulakov, ${ }^{3}$ Elena P. Barylnikova, ${ }^{4}$ Irina P. Talipova \\ ${ }^{1-4}$ Kazan Federal University \\ Email: 692401@mail.ru
}

Received: 20 ${ }^{\text {th }}$ August 2019, Accepted: 30 ${ }^{\text {th }}$ September 2019, Published: $31^{\text {st }}$ October 2019

\begin{abstract}
The main reason for reducing the life of the failed engines in operation is the cranking of the connecting rod inserts. Crankshaft bearings operate under constantly changing loads and speeds, as well as with varying amounts, pressure, temperature and viscosity of the oil supplied to them, which ultimately leads to increased wear on the shaft surface and liners. As the technical condition of the internal combustion engine worsens, stabilization of the available and required oil consumption is not structurally provided, which leads to failures and the need for expensive overhauls. Investigating the reasons for cranking the bushings [1], found that through the crankpin on which the bearings were turned, less oil passed. As a result of the analysis, the need for a deeper study of the conditions of the lubrication process, its influence on the reduction of the engine resource and the need for its stabilization is revealed. A theoretical analysis of the reasons leading to the condition of the rupture of the oil flow to the connecting rod bearings of the internal combustion engine is carried out. The test results of the study of the influence of liner wear on the crankshaft lubrication conditions are presented.
\end{abstract}

\section{Keywords}

Pressure, Oil Consumption, Crankshaft, Lubrication System, Engine, Operational Wear.

\section{Introduction}

The reliability of the crankshaft bearings is achieved by organizing the supply of a sufficient amount of oil to the connecting rod bearings. The main parameter that determines the modes of lubrication is the pressure, which at all steady-state operating modes of the engine should ensure continuity of flow in the channels to the connecting rod bearings $[2,3]$.

To assess the oil pressure in the supply channels to the connecting rod bearings, we consider the process of oil movement through the channels of the crankshaft bearing assembly using the KamAZ-740 diesel engine as an example [4]. In the engine understudy, oil is supplied to the connecting rod bearings (Fig. 1) from the annular channel 1 in the main liner through the channel in the main neck and cheek 2 and the centrifugal dirt catcher 3.

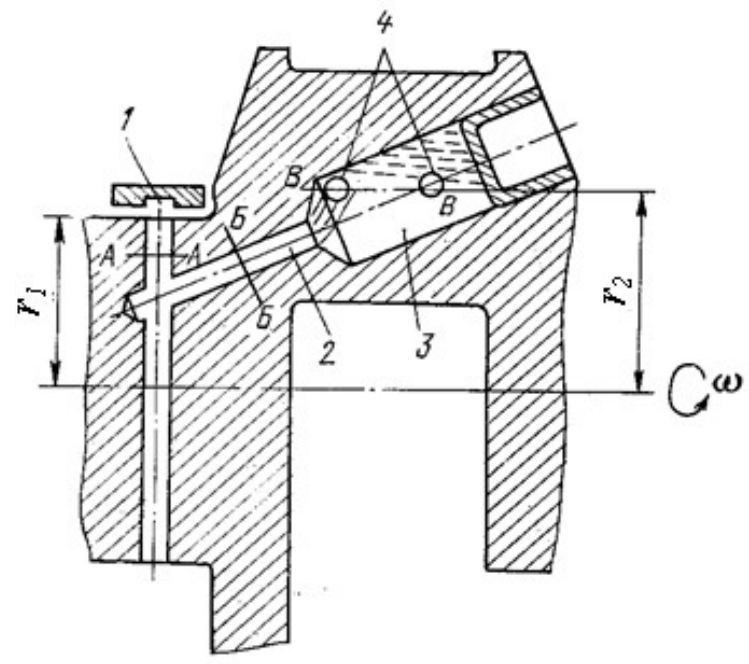

Figure 1: The Scheme for Supplying Oil to the Connecting Rod Bearings

1: Ring channel of the main bearing; 2 and 4: Inclined channel in the cheek and holes for lubrication of connecting rod bearings; 3: Centrifugal mud trap; $r_{1}$ :Radius of the radical neck; $r_{2}$ : Radius of rotation of the outlet holes in the connecting rod bearing (crank)

Such a supply circuit determines the pressure at the inlet to the connecting rod bearing $[5,6,7]$

$P_{o i l 2}=P_{o i l 1}-k P_{o i l 1}-\Delta P_{o i l 1}-\gamma \frac{\omega^{2}}{2 g} r_{1}^{2}+\gamma \frac{\omega^{2}}{2 g} r_{2}^{2}$ 
where $P_{\text {oil } 1}$ - the oil pressure at the inlet to the main bearing; $k$ - loss coefficient due to leaks in the annular channel of the liner; $r_{1}$ - radius of the radical neck; $r_{2}$ - radius of rotation of the outlet holes in the connecting rod bearing (crank); $\omega$ - is the angular velocity; $\gamma-$ is the density of the oil; $g$ - is the acceleration of gravity; $P_{\text {oil } 1}$ - pressure loss during the transition of oil from the groove of the liner into the rotating channel of the crankshaft main bearings.

The components of the oil pressure at the inlet to the connecting rod bearing in the expression (1) are:

- Pressure loss in the annular channel of the main bearing due to leakage in the gap and hydraulic resistance:

$$
\Delta P_{1}=k P_{o i l 1}
$$

- Energy pressure loss during the transition of oil from the groove of the upper mainliner into the rotating channel of the crankshaft in accordance with the Bernoulli equation:

$$
\begin{aligned}
& \Delta P_{\text {oil } 1}=\Delta P_{2}+\Delta P_{3}, \\
& \Delta P_{2}=\gamma \frac{V_{2}^{2}}{2 g}=\gamma \frac{\omega^{2} r_{1}^{2}}{2 g}=\gamma \frac{1}{2 g}\left(\frac{\pi n}{30}\right)^{2} r_{1}^{2} 10^{-4},
\end{aligned}
$$

where $n$ - the speed of the crankshaft, $\min ^{-1}$;

- Pressure loss in the root canal from the deck surface to the axis of the crankshaft from the action of centrifugal forces:

$$
\Delta P_{3}=\gamma \frac{\omega^{2}}{2 g} r_{1}^{2}
$$

- Pressure increment from centrifugal forces in the area from the annular channel of the main bearings to the connecting rod bearings:

$$
\Delta P_{4}=\gamma \frac{\omega^{2}}{2 g} r_{2}^{2} \text {. }
$$

In the modes when $\Delta P_{4}$ is equal to or greater than the oil pressure at the inlet to the connecting rod to the connecting rod journal, the oil flow may break.

The continuity of the oil flow going to the lubrication of the connecting rod bearings is not always ensured. Crankshaft bearings operate under constantly changing loads and speeds, as well as with varying amounts, pressure, temperature and viscosity of the oil supplied to them, which ultimately leads to increased wear on the shaft surface and liners. In addition, wear occurs on the surfaces of the shaft and liners [9]. With increased wear, clearance increases and the flow rate of oil passing through the bearing can also affect lubrication conditions. Disruption of hydrodynamic lubrication due to insufficient oil entering the connecting rod bearings may be a criterion for bearing failure, i.e. a sign of a change in the technical condition of the internal combustion engine, in which the crankshaft bearings are not able to perform the specified functions $[9,10]$.

\section{Methods}

Oil consumption through connecting rod bearings is determined by the oil pressure in the annular channel of the main bearing from which they are fed, the operating mode and the technical condition of the engine [11].

With increased wear, clearance increases and the flow rate of oil passing through the bearing can also affect lubrication conditions. To determine the oil flow rate through the first connecting rod and first crankshaft main bearing, a research technique was developed.

The studies were carried out in two stages on a KamAZ-740 engine. The engine was mounted on a test bench of the AVL company, with a hydraulic brake of the SCHENCK company. The test bench was equipped with the necessary equipment and instruments, the accuracy of which corresponded to the requirements of GOST 14846.

Stage I. Determination of the achievable oil flow through the 1st crank pin.

In the crankshaft of the engine, the oil channel of the 1 st root neck is jammed by installing 1 plug in the channel of the plug (Fig. 2).

On the front flange of the crankshaft, a half-coupling 2 is installed, which was modified so that it can be fixed to it with a fitting with a crane 3, which provides oil supply to the connecting rod bearings along the axis of the crankshaft. An oil pipe is attached to the crane connecting the crane with the crankshaft coupling half. The oil line is connected to the oil flowmeter 4 gear type, the measurement limit of which is 25 liters per minute. The differential valve of the oil pump is blocked. For research, specially selected connecting rod bearings with varying degrees of wear were sequentially mounted on the crankshaft. Before assembling the engine, micrometry is carried out along the diameter of the first connecting rod journal. 


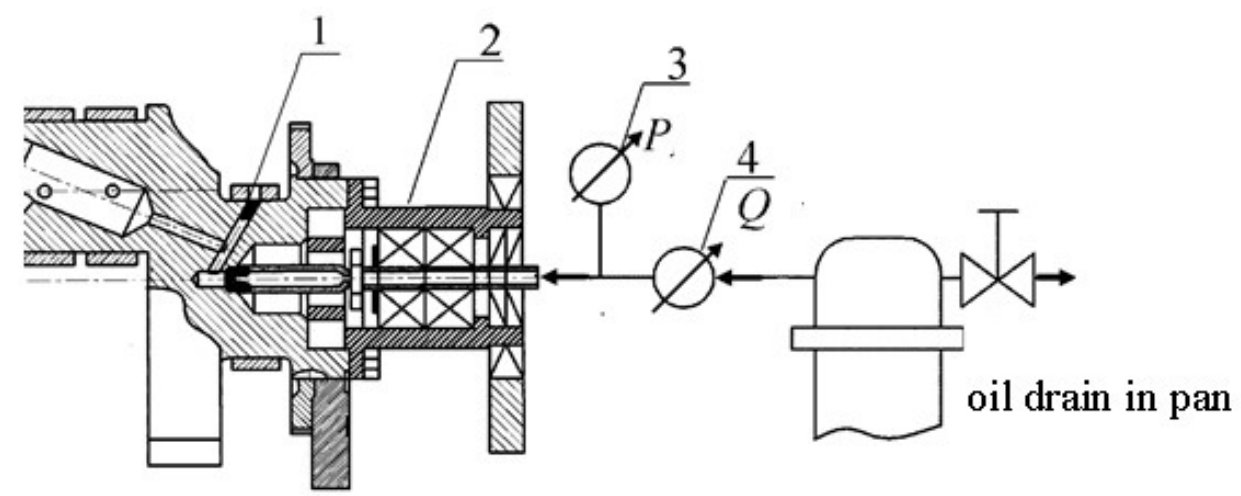

Figure 2: Scheme for Determining the Achievable Oil Flow through the 1st Connecting Rod Neck

The engine is filled with M10 DM oil, the pressure control valve is fully open.

Initially, the oil flow through the connecting rod bearings with a clearance of $0.09 \mathrm{~mm}$ was determined.

After starting the engine, warming it up by adjusting the valve of the crane set the pressure in the lubrication system $\mathrm{P}=$ $0.2 \mathrm{MPa}$.

Removed the high-speed external characteristics of the engine, recording all readings of instruments and sensors, as well as readings of the oil flowmeter.

Then the pressure in the lubrication system was raised to $\mathrm{P}=0.3 \mathrm{MPa}$ and the speed characteristic was taken. So the tests were repeated, gradually raising the pressure in the lubrication system with a crane to $\mathrm{P}=0.7 \mathrm{MPa}$.

Subsequently, connecting rod bushings were installed with wear and clearance of $0.16 \mathrm{~mm}$ in the connecting rod bushings.

The test was repeated, presetting the pressure in the lubrication system from $\mathrm{P}=0.2 \mathrm{MPa}$ to $\mathrm{P}=0.7 \mathrm{MPa}$. All obtained test data were processed and tabulated.

Stage II. Determination of disposable oil flow through the 1st root neck.

To determine the pressure and oil flow rate in the 1st main bearing, an additional hole was drilled in the crankshaft of the engine, which provided oil supply to the bearings of the 1st connecting rod journal from the 2 nd main bearing, and installed in the connecting rod oil supply channel from the 1st main bearing plug 1 (Fig. 3).

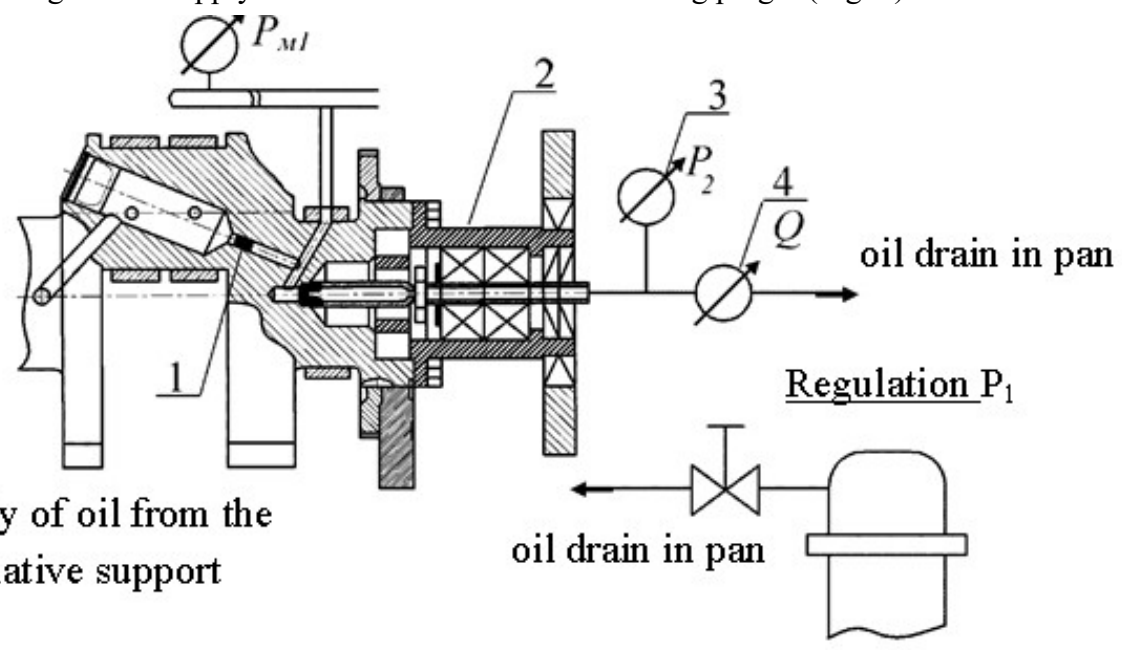

Figure 3: Scheme for Determining the Available Oil Flow through the 1st Root Neck

To the front flange of the crankshaft through the half-coupling 2, an oil pipeline is attached to which a crane with a pressure gauge 3 and an oil flow meter 4 are attached.

From the flowmeter through the oil pipe, the oil was drained into the engine sump, for which the oil pipe was attached to the engine sump by means of a fitting. The differential valve of the oil pump is blocked.

As in the first stage, the main bearings with varying degrees of wear and clearance in the main bearing were successively installed on the crankshaft. Initially, the oil flow rate was determined through the first main bearing, the gap in which was $0.100 \mathrm{~mm}$. Next, the main bearings with wear and clearance in the main bearing of $0.127 \mathrm{~mm}$ were installed. The test was repeated, presetting the pressure in the lubrication system from $\mathrm{P}=0.2 \mathrm{MPa}$ to $\mathrm{P}=0.7 \mathrm{MPa}$.

All obtained test data were processed and tabulated. The data processing results are partially presented in Fig. 4. 
$S_{1}=0,1 \mathrm{~mm} ; S_{2}=0,09 \mathrm{~mm}$

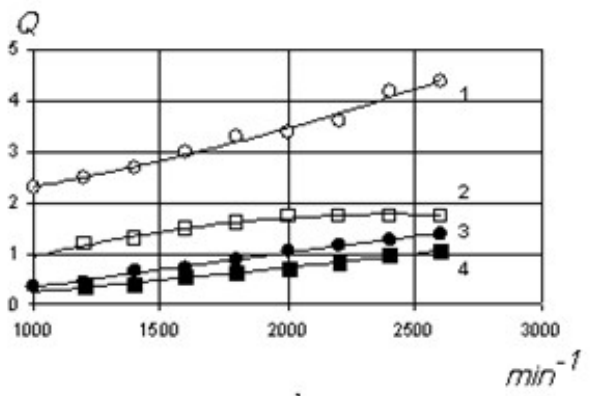

a)

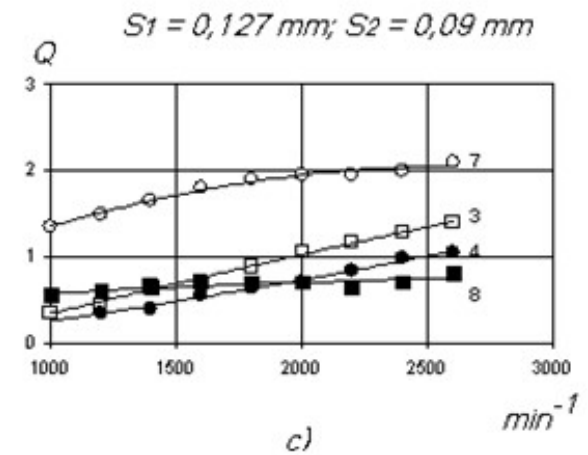

$\mathrm{St}_{1}=0,1 \mathrm{~mm} ; \mathrm{S}_{2}=0,16 \mathrm{~mm}$

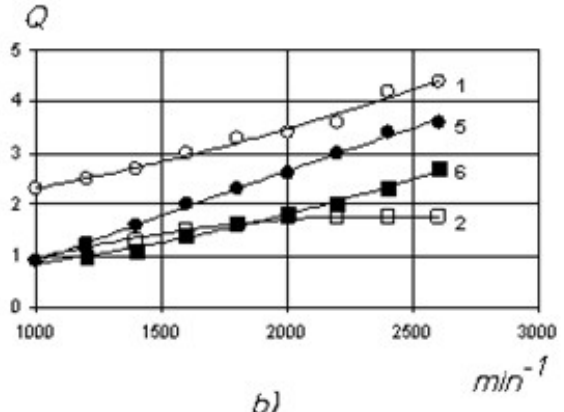

b)

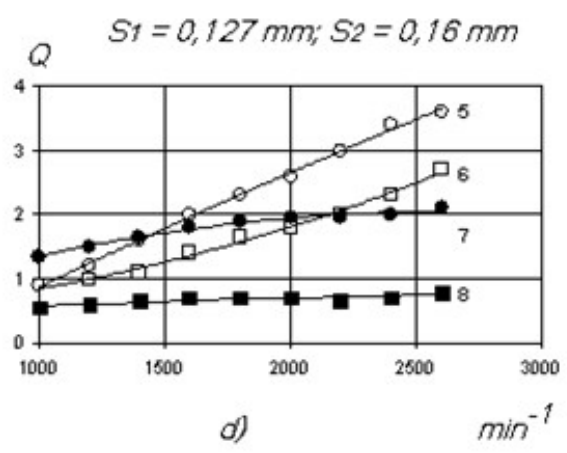

Figure 4: The Dependence of the Oil Flow through the First Root and the First Connecting Rod Bearings to the Rotational Speed of a Crankshaft of the Engine KAMAZ - 740 with Various Combinations of Clearances in

\section{Bearings}

1,2:Tthe flow through the crankshaft bearing with the gap of $0.1 \mathrm{~mm}$ when the oil pressure is, respectively, 0.7 and $0.3 \mathrm{MPa}$; 3,4: Flow rate through the connecting rod bearing when clearance is $0.09 \mathrm{~mm}$ when the oil pressure is, respectively 0.7 and $0.3 \mathrm{MPa}$; 5,6: Flow rate through the connecting rod bearing when clearance is $0.16 \mathrm{~mm}$ when the oil pressure is, respectively, 0.7 and $0.3 \mathrm{MPa}$; 7,8: To flow through the crankshaft bearing when the clearance $0.127 \mathrm{~mm}$ when the oil pressure is, respectively, 0.7 and $0.3 \mathrm{MPa}$; $\mathrm{S}_{1}$ : Amount of the backlash in the radical bearing; $\mathrm{S}_{2}$ : The value of connecting rod bearing clearance

\section{Results and Discussion}

An analysis of the results of stage I test carried out according to the method for determining the oil flow through the first connecting rod journal showed that with a nominal clearance in the connecting rod bearings of $0.09 \mathrm{~mm}$ at a standard pressure of $\mathrm{P}=0.4 \mathrm{MPa}$ and a nominal speed of $\mathrm{n}=2600 \mathrm{~min}^{-1}$ through the connecting rod bearings flows 1.1 liter of oil per minute, and at a speed of $\mathrm{n}=1000 \mathrm{~min}^{-1}$ through the connecting rod bearings flows 0.25 liters per minute. With a decrease in pressure in the system even at $\mathrm{P}=0.3 \mathrm{MPa}$ at revolutions $\mathrm{n}=1000 \mathrm{~min}^{-1}$, the connecting rod bearings begin to experience oil starvation.

With an increase in pressure $\mathrm{P}=0.7 \mathrm{MPa}$ at nominal engine speeds $\mathrm{n}=2600 \mathrm{~min}^{-1}, 1.4$ liters of oil per minute flows through the connecting rod bearings.

When the liners are worn in operation, more oil flows through the connecting rod bearings. Already with worn liners up to $0.035 \mathrm{~mm}$ and a gap in the connecting rod bushings of $0.16 \mathrm{~mm}$ with standard pressure of $\mathrm{P}=0.4 \mathrm{MPa}$ and at a nominal speed of $\mathrm{n}=2600 \mathrm{~min}^{-1} 3.1$ liters of oil flows through the connecting rod liners. At a speed of $\mathrm{n}=1000 \mathrm{~min}^{-1}$ flows 0.7 liters per minute.

With a decrease in pressure to $\mathrm{P}=0.3 \mathrm{MPa}$ and $\mathrm{P}=0.2 \mathrm{MPa}$, the connecting rod bearings begin to experience oil starvation even at $\mathrm{n}=1200 \mathrm{~min}^{-1}$ engine revolutions, i.e. no oil is supplied to lubricate the connecting rod bearings.

At the second stage of testing, the determination of oil flow through the 1 st main bearing at a standard pressure of $\mathrm{P}=$ $0.4 \mathrm{MPa}$ and with a nominal clearance in the main bearings is $0.1 \mathrm{~mm}, 2.8$ liters of oil per minute are supplied to the connecting rod bearings, i.e. disposable flow rate is higher than achievable.

At nominal pressures up to $\mathrm{P}=0.3 \mathrm{MPa}$ already at revolutions $\mathrm{n}=1000 \mathrm{~min}^{-1}$ the oil is not supplied to the connecting rod bearings. At a pressure of $\mathrm{P}=0.2 \mathrm{MPa}$ already at revolutions $\mathrm{n}=1400 \mathrm{~min}^{-1}$ oil is not supplied.

\section{Summary}

1. The oil flow supplied to the connecting rod bearings is determined by the oil pressure in the annular channel of the main bearing and losses associated with the transition from the annular stationary channel of the liner to the rotating channels of the crankshaft. 
2. The oil pressure at the inlet of the connecting rod bearing is lower than the pressure in the main bearing by the amount of centrifugal losses and losses during the transition from the channel of the main bearing to the channel of the main neck.

3. With a decrease in pressure, due to the action of centrifugal forces, "dynamic locking" of the channel in the root neck can occur and, when the oil pressure is equal at the end of the root neck channel and the pressure increases from centrifugal forces in the section from the center of the shaft to the hole in the crankpin oil flow into the connecting rod bearing.

\section{Conclusions}

The operational wear of the crankshaft bearings can lead to the rupture of the oil flow to the connecting rod bearings of the engine. If, at normal clearances, the available oil flow through the channels of the main bearings is sufficient to pump the required oil flow through the connecting rod bearings, then with an increase in the clearances, the required oil flow into the connecting rod bearings can be several times higher than the available oil flow through the main bearings. The study made it possible to establish the limiting value of pressure in the engine lubrication system, which can be described as a critical pressure point. Preventing the pressure in the lubrication system below $0.26 \mathrm{MPa}$ allows you to save a margin in the performance of the available oil flow over the required flow rate through the connecting rod bearings of the crankshaft and thereby eliminate their premature failure.

\section{Acknowledgments}

The work is performed according to the Russian Government Program of Competitive Growth of Kazan Federal University.

\section{References}

[1] A.S. Denisov Analysis of the causes of operational damage to the connecting rod bearings of the KamAZ-740 / AS engines A.T. Denisov, Kulakov // Engine building. 1981. No. 9. - pp. 37-40.

[2] A.A. Gafiyatullin. Ensuring the operability of connecting rod bearings of automotive engines by creating the continuity of the oil flow / A.A. Gafiyatullin. Dis. Cand. tech. sciences. Saratov, 2005. - 130 pages.

[3] N.I. Svetlichny. Improving the reliability of KamAZ engines by reducing the failure of connecting rod bearings in operation / N.I. Svetlichny. Dis. Cand. tech. sciences. Saratov. 2001, 157 pages.

[4] Manual for maintenance and repair of automobiles KamAZ / Ed. by V.N. Baruna - 2nd ed., Rev. and add. - M .: Transport, 1988. - 352 pages.

[5] M. A. Grigoriev. Ensuring engine reliability / M.A. Grigoryev, V.A. Doletsky. M .: Publishing house of standards, 2016. - 40 pages.

[6] A. Schillinq. Les huiles pour Motuvs et le qraissage des Moteuvs, Vol. II, 1962.

[7] A.T. Kulakov. A.T. Barylnikova, A.A. Gafiyatullin. "Providing normal conditions of lubricating of diesel engine during its operation". // IOP Conference Series: Materials Science and Engineering. - Volume 69, Issue 1, 2014, No. 012027012027.

[8] I.A. Sakhapov. Improving the reliability of automotive engines by reducing the deformation of the connecting rod bearings / I.A. Sakhapov. Dis. Cand. tech. sciences. Saratov. 2009 .- 143 pages.

[9] A.T. Kulakov. Improving the reliability of automotive diesel engines by improving the process of lubrication, cleaning and repair technology of the main elements: diss. ... Dr. tech. Sciences: 05.20.03 / A.T. Kulakov. Saratov, 2007 .- 558 pages.

[10] A.T. Kulakov, A.T. A.T. Barylnikova, A.T. Kulakov "Adaptive system of supplying lubricant to the internal combustion engine” IOP Conf. Series: Materials Science and Engineering Vol. 240 (2017) 012010.

[11] Barylnikova A.T. Increasing the resource of automobile engines by stabilizing the lubrication mode of connecting rod bearings in operation: diss ... cand. tech. Sciences: 05.22.10 // A.T. Barylnikova - Orenburg. 2013. 